\title{
Optimisation of bio-oil production by hydrothermal liquefaction of agro-industrial residues: Blackcurrant pomace (Ribes nigrum L.) as an example
}

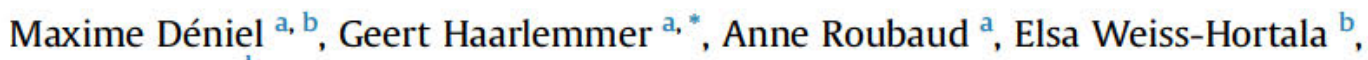 \\ Jacques Fages ${ }^{b}$ \\ a CEA-LITEN, Laboratoire de Thermo-conversion des Bioressources, 17 rue des Martyrs, 38054 Grenoble, France \\ ${ }^{\mathrm{b}}$ Université de Toulouse, Ecole des Mines d'Albi, CNRS Centre RAPSODEE, 81013 Albi, France
}

\begin{abstract}
A B S T R A C T
This work reports bio oil production by hydrothermal liquefaction of blackcurrant pomace (Ribes nigrum $\mathrm{L}$ ), a fruit residue obtained after berry pressing. The bio oil has a higher heating value of $35.9 \mathrm{MJ} \mathrm{kg}{ }^{1}$ and low ash content, which makes it suitable for energy applications. We report the influence of process parameters on yields and carbon distribution between products: temperature (563 $608 \mathrm{~K}$ ), holding time ( $0240 \mathrm{~min}$ ), mass fraction of dry biomass in the slurry $(0.05 \quad 0.29)$, and initial $\mathrm{pH}\left(\begin{array}{ll}3.1 & 12.8\end{array}\right)$ by adding sodium hydroxide $(\mathrm{NaOH})$. Depending on the experiments, the bio oil accounts for at least $24 \%$ mass fraction of the initial dry biomass, while char yields ranges from 24 to $40 \%$. A temperature of $583 \mathrm{~K}$ enhances the bio oil yield, up to $30 \%$, while holding time does not have a significant influence on the results. Increasing biomass concentrations decreases bio oil yields from $29 \%$ to $24 \%$. Adding sodium hydroxide decreases the char yield from $35 \%$ at $\mathrm{pH}=3.1$ (without $\mathrm{NaOH}$ ) to $24 \%$ at $\mathrm{pH}=12.8$. It also increases the bio oil yield and carbon transfer to the aqueous phase. Thermogravimetric analysis shows that a $43 \%$ mass fraction of the bio oil boils in the medium naphtha petroleum fraction range. The bio oil is highly acidic and unsaturated, and its dynamic viscosity is high (1.7 Pa s at $298 \mathrm{~K}$ ), underlining the need for further upgrading before any use for fuel applications.
\end{abstract}

\section{Introduction}

Hydrothermal processing of biomass using water in sub and supercritical conditions has been identified as a promising tech nology to convert wet resources into energy dense products in the form of solid, liquid or gaseous fuels [ 13 3]. Hydrothermal processes take advantage of the evolution of water properties at high tem perature and pressure [4]. In particular under subcritical condi tions, water loses its polarity, behaving similar to an organic solvent, and its ionic product $\mathrm{K}_{\mathrm{w}}$ increases up to three orders of magnitude [2]. These two modifications of water properties lead respectively to better solubility of organic compounds and increased catalytic activities to degrade the molecules contained in biomass.

In these conditions, liquid fuels can be directly produced from wet biomass by the hydrothermal liquefaction (HTL) process $(\mathrm{T}=523643 \mathrm{~K}, \mathrm{P}=10 \quad 30 \mathrm{MPa})$. The HTL process is generally seen as a sustainable and energy efficient process [3], as it converts wet biomass into four valuable streams: a crude like bio oil with higher heating values up to $3540 \mathrm{MJ} \mathrm{kg}^{-1}$, an aqueous phase containing light polar platform chemicals, a combustible solid residue called 'char' and a $\mathrm{CO}_{2}$ rich gaseous phase also containing certain amounts of hydrogen and light hydrocarbons. Hydrothermal liquefaction has been applied to a wide range of resources from wood [5] to algae [6] and food processing residues [7]. The latter are of particular interest for valorisation through hydrothermal lique faction, as they contain a significant amount of valuable organic matter and are often wet resources, containing more than $50 \%$ water in weight.

Food processing residues are produced at every stage of the food supply chain, from harvesting to final consumption [8]. They currently represent more than $20 \%$ of the total mass of agricultural production in the world, but increasing urbanisation,

\footnotetext{
* Corresponding author.

E-mail address: geert.haarlemmer@cea.fr (G. Haarlemmer).
} 
industrialisation and population growth worldwide are responsible for increased generation of this type of wastes [9,10]. Dealing with the large amount of food processing residues generated each year is a critical issue, because when badly managed, they can contribute to environmental and sanitary problems. It is also necessary to consider the increasingly limited space available for disposal, which is favourable to developing alternative ways of valorisation. Food and agricultural wastes represent a widely available source for valorisation; either by recovering high value compounds from extraction or separation processes $[11,12]$ or by producing bio based fuels. In particular, fruit processing residues are relevant for valorisation, because this industry is one of the main producers of food wastes: up to $50 \%$ mass fraction of fruits and vegetables are lost along the food supply chain [13].

Although many research papers report hydrothermal liquefac tion of various resources, a limited number of studies focuses on food processing residues, and even fewer on fruit and vegetable processing residues [14 22]. Wang et al. [18] obtained a maximum bio oil yield of $56.9 \%$ after HTL of Litsea cubeba seed at $563 \mathrm{~K}$, 60 min. Akalın et al. [16] performed HTL of cornelian cherry stones and obtained a maximum total bio oil yield of $28 \%$. Grape seeds were hydrothermally treated by Yedro et al. [19], resulting in $15.7 \%$ of light bio oil yield (diethyl ether soluble) and $16.2 \%$ heavy bio oil yield (acetone soluble) at $613 \mathrm{~K}$. Previous studies used alkali salts as additives to improve the bio oil yields by carrying out hydrother mal liquefaction in basic medium. Karagöz et al. [23] reported an increased oil yield from $17.8 \%$ to $33.7 \%$ when using $\mathrm{K}_{2} \mathrm{CO}_{3}$ at increasing concentrations from 0.235 to $0.94 \mathrm{~mol} \mathrm{~L}^{-1}$. This also led to a reduction of the char yield and higher recovery of water soluble organics. Sodium hydroxide, $\mathrm{NaOH}$, was used by many au thors, e.g. Sugano et al. [24] to reduce char yield and increase the bio oil recovery. Yin et al. [25] also performed HTL of cattle manure in presence of $\mathrm{NaOH}$ to increase the conversion and the bio oil yield. Even though a large number of studies have been reported in the literature, the methods and resources are extremely variable. Therefore systematic studies on specific resources are required both for resource screening and comparison purposes.

We report in this paper a systematic study of HTL of black currant pomace (Ribes nigrum L.). This wet resource requires costly drying prior to combustion. It is also a more complex matrix than wood, making it more suitable for HTL due to the presence of lipids and proteins and a lower proportion of lignin. Under similar con ditions, beech wood produces a very viscous oil rich in phenolic compounds [26]. We chose this resource because it is representa tive of fibrous residues recovered after fruit pressing, mainly constituted by seeds, peels and pulp. The literature is quite poor regarding HTL of fruit pomace, and this study is to our knowledge the first dealing with hydrothermal conversion of blackcurrant pomace. The influence of several process parameters on HTL of blackcurrant pomace have been evaluated, with the objective of producing bio oil in high yields: reaction temperature (563 $608 \mathrm{~K}$ ), holding time (0 $240 \mathrm{~min}$ ) and mass fraction of dry biomass in the slurry $(0.050 .29)$. We also report observations on the impact of adding sodium hydroxide to vary the initial $\mathrm{pH}$ of the feed (3.1 12.8). Finally, analytical data on the molecular composi tion as well as some properties of the bio oil are reported, which are important information for further upgrading studies.

\section{Materials and methods}

First, the resource used for the experiments is presented. Sec ondly, experimental procedures for hydrothermal liquefaction are described together with recovery and analysis of products.

\subsection{Materials}

Blackcurrant (Ribes nigrum L.) pomace was the substrate used in the experiments. It was supplied by Les Vergers Boiron, a local producer of fruit purees and coulis operating in Valence, France. Blackcurrant pomace was obtained as a pressing residue of berries from mixed cultivars, namely Noir de Bourgogne and Andega. The biomass is the press cake recovered from juice production, mainly constituted by seeds, peels and pulp: it is a wet and fibre rich biomass, also containing certain amounts of proteins and lipids. Table 1 gives the composition and Higher Heating Value (HHV) of the biomass.

For hydrothermal liquefaction experiments, distilled water was used. Pellets of sodium hydroxide $\mathrm{NaOH}$ were purchased from Merck and used as received. Ethyl acetate used for bio oil recovery was purchased from Sigma Aldrich and used as received.

\subsection{Hydrothermal liquefaction}

In this section, we first present our experimental procedure for HTL experiments. We focus secondly on the recovery and analysis of products.

\subsubsection{HTL experiments}

Hydrothermal liquefaction experiments were performed in a 0.6 L stainless steel (type 316) stirred batch reactor (Parr In struments). In a typical experiment, the reactor was filled with approximately $240 \mathrm{~g}$ of biomass slurry prepared from raw black currant pomace, distilled water and a certain amount of $\mathrm{NaOH}$ when needed. Before each experiment, $\mathrm{pH}$ was measured (Scien tific Instruments IQ170 pH meter). The initial pH of the raw slurry without additives was 3.1. The $\mathrm{pH}$ was measured at 5.5, 7.4, 10.8, and 12.8 , when adjusting the quantity of $\mathrm{NaOH}$ to respectively 2,3 , 5 , and $9 \%$ mass fraction of the dry biomass. The autoclave was leak tested, purged and pressurised to $1 \mathrm{MPa}$ with nitrogen gas to guarantee sufficient pressure for gas analysis after the reaction. The total pressure inside the reactor was a function of the reaction temperature, the amount of water and of gas produced. The reactor was heated from room temperature to the reaction temperature in about $3540 \mathrm{~min}$. Reaction temperatures were between $563 \mathrm{~K}$ and $608 \mathrm{~K}$. Once the reactor reached the reaction temperature, it was held during a specified holding time within $\pm 1 \mathrm{~K}$ of the reaction temperature. Holding times were between 0 and $240 \mathrm{~min}$. A stir ring speed of $10 \mathrm{~Hz}$ was set. After the holding time, the reactor was

\section{Table 1}

Characterisation of blackcurrant pomace

(HHV: Higher Heating Value; NDF: Neutral Detergent Fibres; ADF: Acid Detergent Fibres; ADL: Acid Detergent Lignin).

\begin{tabular}{lll}
\hline Blackcurrant Pomace & & Standard \\
\hline Moisture content (\%) & 59.6 & EN 14774-1 \\
Fibre content (\% of dry matter) & & NF V18-122 \\
NDF & 61.7 & \\
ADF & 52.8 & \\
ADL & 35.4 & \\
Proteins (\% of dry matter) & 16.9 & Internal method \\
Lipids (\% of dry matter) & 14.8 & Internal method \\
Ash content at 823 K (\% of dry matter) & 4.3 & NF EN 14775 \\
Elemental composition & & NF EN 15104 \\
(\% of dry matter) & & \\
C & 50.3 & \\
H & 6.8 & \\
O & 36.8 & (by difference) \\
$\mathrm{N}$ & 1.9 & \\
$\mathrm{~S}$ & 0.2 & \\
HHV (MJ kg ${ }^{1}$ ) & 18.51 & NF EN 14918 \\
\hline
\end{tabular}


rapidly cooled down to room temperature in $20 \mathrm{~min}$ by an air quench. Experiments at the highest temperature of $608 \mathrm{~K}$ required the use of a different reactor capable of supporting higher pres sures, described in Huet et al. [27], having a similar operating procedure. The gas in the reactor was vented and analysed by a micro chromatograph (Varian Quad CP 4900) used on line. Per manent gases $\left(\mathrm{O}_{2}, \mathrm{H}_{2}, \mathrm{CO}\right.$ and $\left.\mathrm{CH}_{4}\right)$ were analysed by a molecular sieve column using argon as carrier gas. Light hydrocarbons $\left(\mathrm{C}_{2} \mathrm{H}_{4}\right.$, $\mathrm{C}_{2} \mathrm{H}_{6}, \mathrm{C}_{2} \mathrm{H}_{2}$ and $\left.\mathrm{C}_{3} \mathrm{H}_{8}\right), \mathrm{CO}_{2}$ and sulphur species $\left(\mathrm{H}_{2} \mathrm{~S}\right.$ and $\left.\mathrm{COS}\right)$ were analysed on a Poraplot $\mathrm{U}$ column using helium as carrier gas. Solid and liquid products were then recovered following the recovery procedure described in paragraph 2.2.2.

\subsubsection{Product recovery procedure}

After gas analysis, the reactor was opened and the products were recovered following the procedure given in Fig. 1. The content of the reactor was first filtered on a Buchner filter to separate the aqueous phase from the raw organic residue. The raw organic residue was sticky, and removed from the reactor as best as possible. The reactor was then weighed and the weight difference with the empty reactor was counted as remaining raw organic residue (wet). As illustrated by Fig. 1, the material left in the reactor was taken into account in the calculation of the mass yields. Moisture content of the raw organic residue $\left(W_{R}\right)$ was estimated using two methods: drying at room temperature under air circu lation until a stable mass was obtained, and Karl Fischer titration using a Schott Instruments Titroline KF. Combination of the two methods allows evaluating the experimental error due to estima tion of the moisture content of the raw organic residue.

Depending on the proportion of bio oil and char, the aspect of the raw organic residue can vary from an oily solid to a free flowing viscous residue. When the amount of char is high, the bio oil cannot be directly valorised and solvent extraction is necessary to separate the liquid from the solid fraction. We chose ethyl acetate to recover the bio oil, because it allows good bio oil recovery, it is non toxic, and has a low miscibility with water. The raw organic residue was then extracted using a tenfold mass of ethyl acetate to separate the bio oil from the char on a Buchner filter. Bio oil was recovered after evaporation of ethyl acetate at room temperature under air circulation, until a stable weight was obtained. An esti mation of the amount of residual solvent in the bio oil was per formed by dissolving the bio oil recovered after ethyl acetate evaporation in 2 propanol, followed by GC MS analysis. The anal ysis showed that only traces of ethyl acetate were left after evap oration. It was therefore assumed that no significant amount of residual solvent was left in the bio oil. The char was also dried at room temperature under air circulation until a stable weight was obtained. Weight loss of the char after extraction and drying was used to determine the proportion of solvent soluble organics in the raw organic residue (SSO), and therefore the bio oil yield. Calcu lation of the yields is explained in detail in the supplementary material.

Mass yields were calculated from the obtained experimental results. They are defined as the mass ratios between the recovered phases and the dry biomass used in the experiment. Detailed cal culations are explained in the supplementary information. Only the bio oil $\left(\mathrm{Y}_{\mathrm{BO}}\right)$, char $\left(\mathrm{Y}_{\mathrm{C}}\right)$ and gas $\left(\mathrm{Y}_{\mathrm{G}}\right)$ yields are reported in this paper. In fact, the quantity of organic matter in the water phase is difficult to assess by simple drying as many compounds are volatile. In the literature, the aqueous phase yield is sometimes calculated by

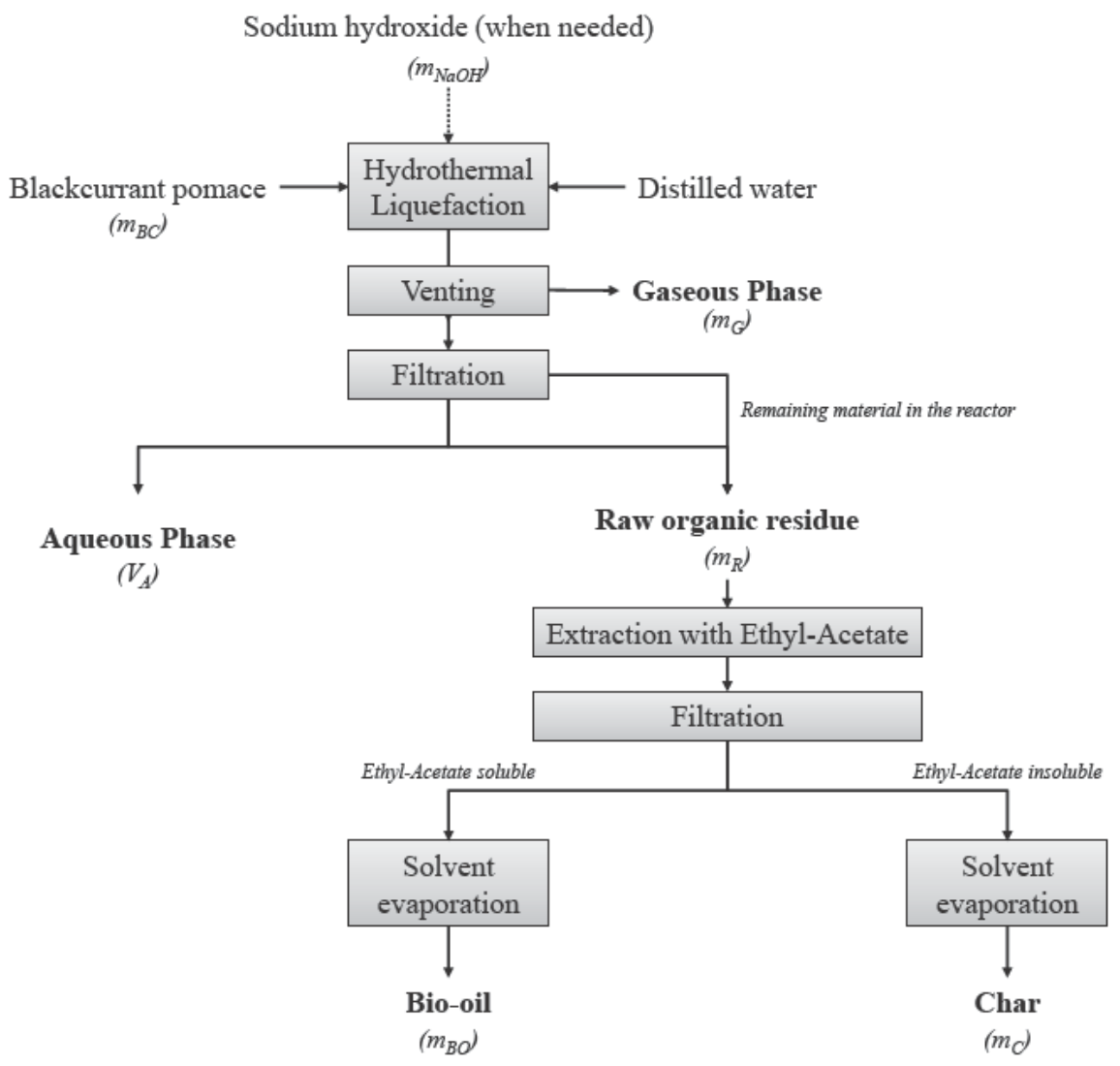

Fig. 1. Recovery procedure for products after hydrothermal liquefaction of blackcurrant pomace. 
difference, closing the mass balance on the organic matter to $100 \%$ $[28,29]$. By doing so, the aqueous phase yield integrates the mass balance closure error. Due to hydration and dehydration reactions, the overall organic mass balance does not necessarily close to $100 \%$. Therefore, we do not report the mass yield of organics in the aqueous phase together with the mass yield of the other phases, since it cannot be accurately determined. However, carbon recov ery in the aqueous phase can be determined and is reported. Car bon recoveries are defined as the ratios between the mass of carbon contained in the recovered phases and the initial mass of carbon in the biomass. Detailed calculations are explained in the supple mentary information.

In the results and discussion section, reported experimental values are the mean values of two replicates of each experiment. Error bars represent the standard deviations. Unless otherwise indicated, "\%" refers to mass percentages.

\subsubsection{Analysis of products}

Total carbon of the solid and oil samples were quantified by a total carbon analyser (Shimadzu SSM $5000 \mathrm{~A}$ ). Total carbon of the aqueous phase $\left(\mathrm{CT}_{\mathrm{A}}\right)$ was quantified by a total organic carbon analyser (Shimadzu TOC L CSH/CSN). Elemental analysis of the bio oil was performed on a CHNS analyser Elementar Vario El Cube. Ash contents of the bio oil and char samples were determined by burning the samples in air at $823 \mathrm{~K}$ according to the EN14775 standard. Higher heating values of solid and oil samples were measured using a Parr 6200 bomb calorimeter.

For experiments involving $\mathrm{NaOH}$, the sodium content of the aqueous phase was determined by ion chromatography using a Dionex ICS3000 equipped with a Dionex IonPac CS 16 column $(5 \times 250 \mathrm{~mm})$ and a Dionex IonPac CG 16 guard column $(5 \times 50 \mathrm{~mm})$. A $25 \mathrm{~mm}^{3}$ injection volume of diluted sample was used. A $48 \mathrm{mmol} \mathrm{L}^{-1}$ solution of Methanesulfonic acid (MSA) was used as eluent in isocratic conditions with a $1 \mathrm{~cm}^{3} \mathrm{~min}^{-1}$ flowrate. The column temperature was maintained at $303 \mathrm{~K}$. The sodium content of the aqueous phase generated in the absence of $\mathrm{NaOH}$ was measured by the same procedure.

The molecular composition of the bio oil was analysed by a Gas Chromatograph coupled with a Mass Spectrometer, GC MS (Clarus 500/Clarus 600 S, Perkin Elmer, USA) equipped with a DB 1701 capillary column $60 \mathrm{~m} \times 0.25 \mathrm{~mm}, 0.25 \mu \mathrm{m}$ film thickness. A $1 \mathrm{~mm}^{3}$ sample was injected into the instrument with a split ratio of 10:1. Helium was used as carrier gas. The GC oven temperature was programmed from $318 \mathrm{~K}(10 \mathrm{~min})$ to $503 \mathrm{~K}$ at a rate of $6 \mathrm{~K} \mathrm{~min}^{-1}$, and held at $503 \mathrm{~K}$ during $9.17 \mathrm{~min}$. It was then raised to $523 \mathrm{~K}$ at a rate of $10 \mathrm{~K} \mathrm{~min}^{-1}$, and held at $523 \mathrm{~K}$ during $20 \mathrm{~min}$. The NIST mass spectral database was used to identify the peaks. For GC/MS anal ysis, a mass ratio of raw organic residue to ethyl acetate of $1: 1$ was used to minimise the effect of potential solvent pollution on the chromatograms.

Thermogravimetric analysis (TGA) of the bio oil was performed to evaluate the boiling point distribution of the bio oil and the fraction of bio oil analysed by GC MS, using a Setaram Setsys Evolution apparatus. A bio oil sample of $56 \mathrm{mg}$ in a platinum crucible was heated from $333 \mathrm{~K}$ to $1173 \mathrm{~K}$ at a rate of $10 \mathrm{~K} \mathrm{~min}^{-1}$ to let it evaporate under a $50 \mathrm{~cm}^{3} \mathrm{~min}^{-1}$ nitrogen flow at atmospheric pressure. The boiling point distribution was evaluated according to the classification proposed by Speight for petroleum products [30].

Total Acid Number (TAN), iodine value, density and dynamic viscosity of the bio oil were determined according to the methods described in Anouti et al. [31].

\section{Results and discussion}

We report in this section the effect of several process parameters, as well as the influence of adding sodium hydroxide $\mathrm{NaOH}$ to increase the initial $\mathrm{pH}$ of the feed. Some properties of the bio oil relative to molecular composition and fuel specifications are also reported in section 3.3.

\subsection{Effect of operating conditions}

In this sub section we report the effect of several operating conditions on HTL of blackcurrant pomace: reaction temperature between $563 \mathrm{~K}$ and $608 \mathrm{~K}$, holding time between 0 min and $240 \mathrm{~min}$ and mass fraction of dry biomass in the reaction slurry between 0.05 and 0.29 .

\subsubsection{Effect of reaction temperature}

The effect of the reaction temperature on HTL of blackcurrant pomace was evaluated between $563 \mathrm{~K}$ and $608 \mathrm{~K}$, with a fixed 60 min holding time and a fixed mass fraction of dry biomass in the slurry of 0.14 . Fig. 2 shows the effect of the reaction temperature on the products and carbon distribution. Global mass balances and carbon balances vary from $103 \%$ to $111 \%$, which is relatively good considering the experimental error for this set of experiments.

The results show that increasing the temperature from $563 \mathrm{~K}$ to $583 \mathrm{~K}$ tends to enhance the bio oil yield and carbon recovery in the bio oil, associated with lower char yields. Higher temperatures lead to a slight decrease of the bio oil yield and to a slight increase of gas formation. This is consistent with most published studies in the
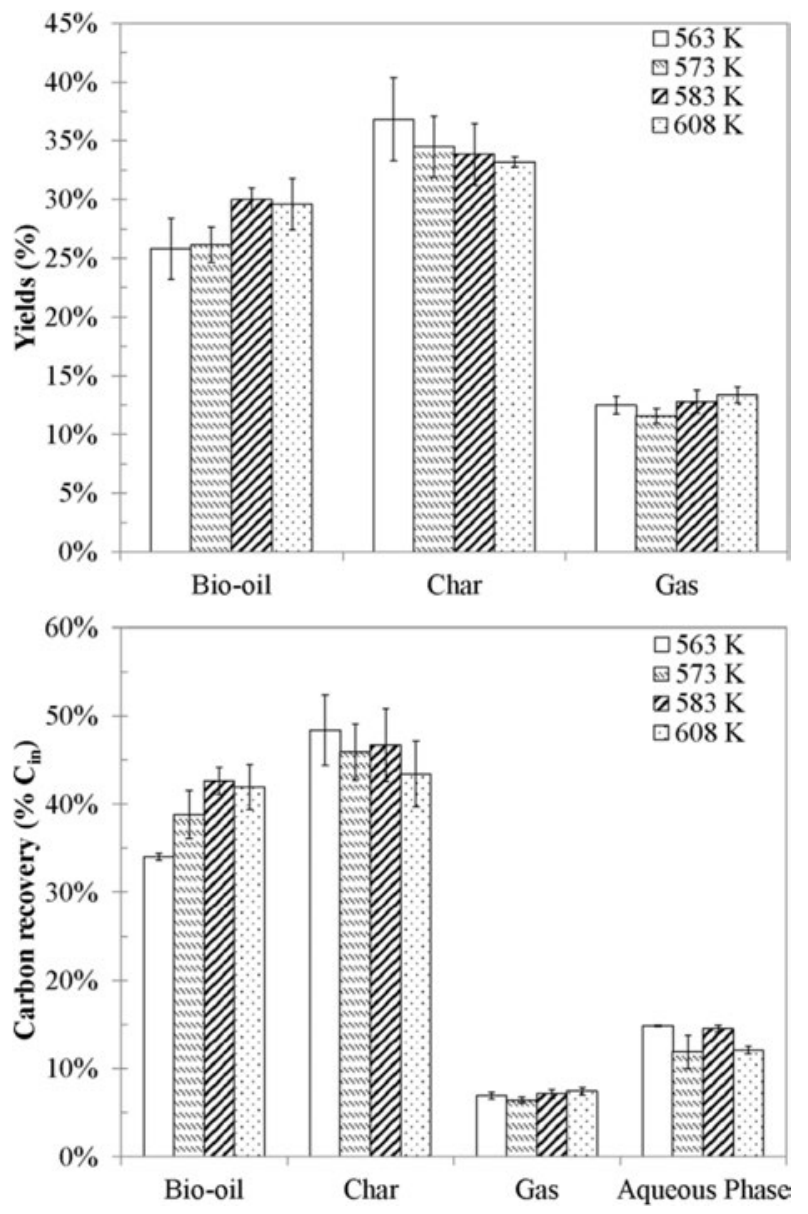

Fig. 2. Effect of reaction temperature on products distribution and carbon recovery (holding time $60 \mathrm{~min}$ ). 
literature [32]. In addition, these experimental observations can be linked to the pathway of bio oil formation.

In subcritical water, biomass is first hydrolysed and releases reactive monomers in the reaction medium. Depending on the resource composition, hydrolysis of biopolymers requires different levels of temperatures. Amorphous hemicelluloses are hydrolysed at lower temperatures than cellulose, while lignin conversion re quires higher temperatures than cellulose. This is for instance the observation made by Karagöz et al. [33], who reported that cellu lose was converted at $70.1 \%$ at $553 \mathrm{~K}$, while lignin was only con verted at $40.0 \%$ and produced more solid residue. The characterisation of blackcurrant pomace showed that it is a particularly fibrous biomass, with high cellulose and lignin con tents (Table 1). This might explain that a better conversion is ob tained at temperatures above $310{ }^{\circ} \mathrm{C}$.

Hydrolysis of biopolymers releases reactive monomers in the reaction medium, which degrade subsequently to give light polar molecules found in the aqueous phase, as well as bio oil and char through condensation and polymerisation reactions. Gaseous products originate either from degradation of water soluble prod ucts (decarboxylation, decarbonylation) or from bio oil decompo sition by steam reforming reactions [25,34]. Gas formation pathways are favoured with increasing temperatures, due to frag mentation reactions. In the temperature range that we considered, the gaseous phase is mainly formed by $\mathrm{CO}_{2}(>95 \%)$, because of decarboxylation, decarbonylation and Water Gas Shift reactions. Fig. 2 also shows that a non negligible amount of char is produced. This is probably due to the highly fibrous nature of the resource, particularly the high lignin content, and to repolymerisation of reactive intermediates both in the aqueous phase and in the bio oil. For instance, self condensation of the bio oil fraction formed by lignin depolymerisation can occur, leading to polymeric structures found in the char. As well, operating in batch mode might lead to more char than what could be expected because of long heating and cooling periods, as we discuss in section 3.1.2.

From the data presented in Fig. 2, we see that a temperature near $583 \mathrm{~K}$ appears to be adapted to increase the bio oil recovery, while higher temperatures might lead to more gas. The results illustrate the synergetic effect between high dissociation of water and thermal activation of bond cleavage. The temperature has to be high enough to ensure that biopolymers such as cellulose and lignin are hydrolysed and participate in bio oil formation. For the following experiments, we chose a fixed temperature of $573 \mathrm{~K}$, which allows a good bio oil recovery and a safer operation of our experimental device.

\subsubsection{Effect of holding time}

The effect of holding time on HTL of blackcurrant pomace was evaluated at a fixed temperature of $573 \mathrm{~K}$ and a fixed mass fraction of dry biomass in the slurry of 0.14 . Holding times were varied from 0 min (immediate cooling after heating to the reaction tempera ture) to $240 \mathrm{~min}$. A holding time of $0 \mathrm{~min}$ allows determining the impact of the heating time associated with using a batch reactor. Fig. 3 shows the effect of holding time on the products and carbon distribution. Global mass balances and carbon balances are gener ally good as they vary from $101 \%$ to $112 \%$ for this set of experiments.

The results show that the holding time has no significant in fluence on the yields. This observation suggests that the majority of reactions occurred in the early stages of the process, possibly dur ing the relatively long heating period of the batch autoclave. In fact, it is well agreed that hydrothermal liquefaction is a fast process: hydrolysis of biopolymers and degradation of monomers generally occur within seconds to a few minutes [35]. It is therefore likely that hydrothermal conversion of blackcurrant pomace also occurs rapidly. Fig. 4 shows a typical heating and cooling profile at a

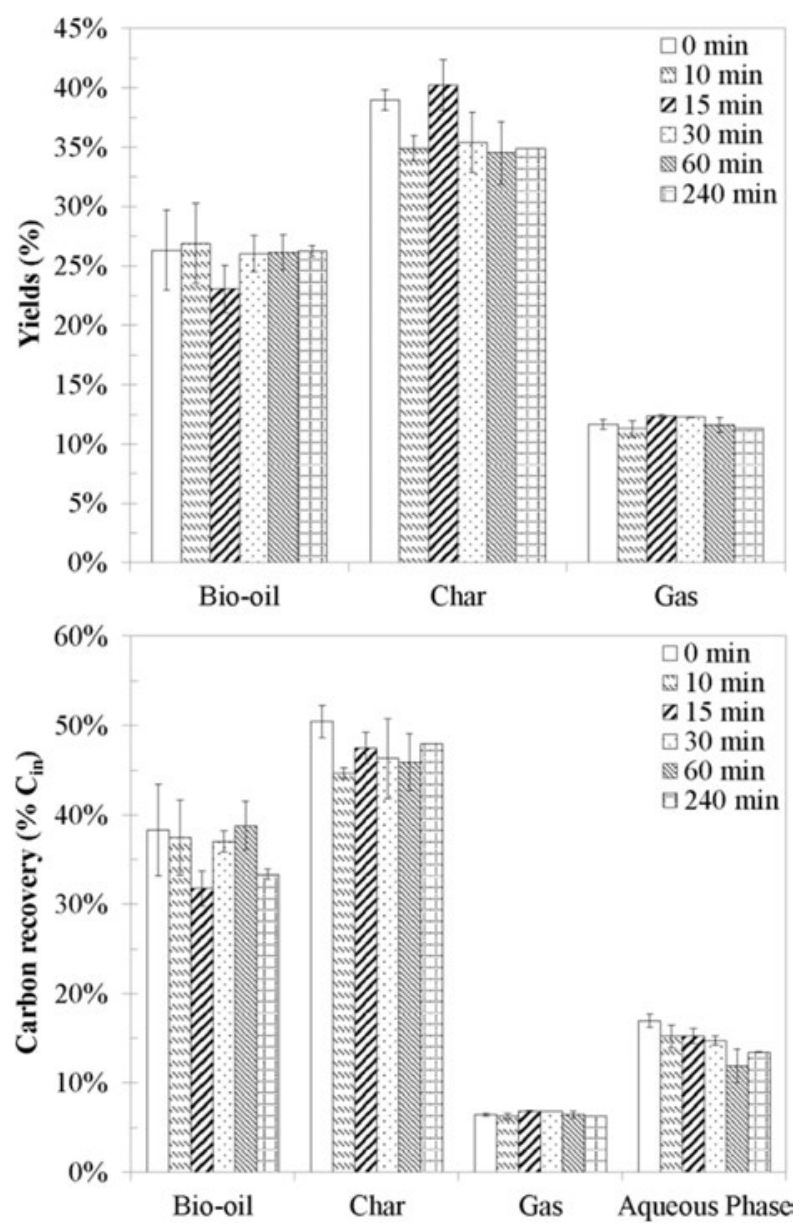

Fig. 3. Effect of holding time on products distribution and carbon recovery (reaction temperature $573 \mathrm{~K}$ )

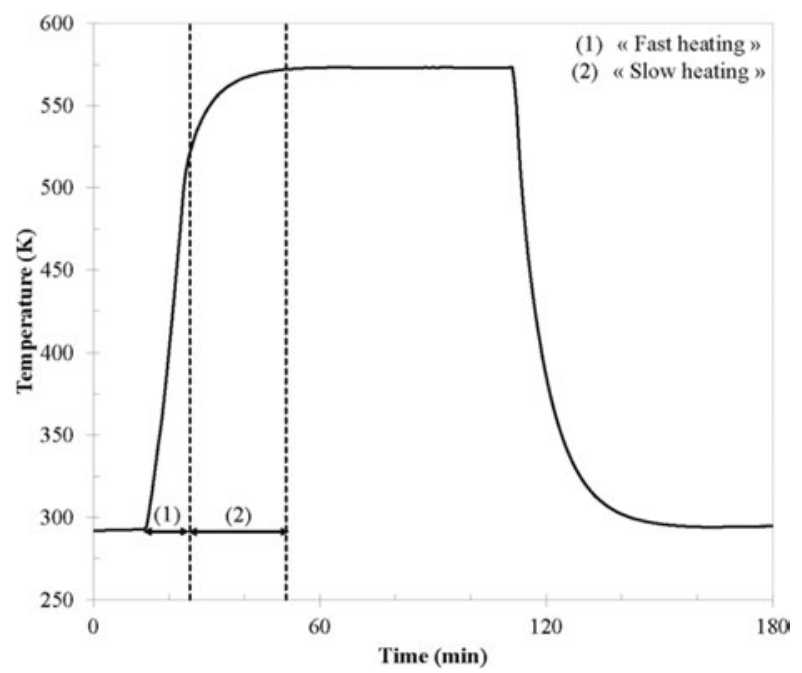

Fig. 4. Temperature profile recorded during HTL of blackcurrant pomace (reaction temperature $573 \mathrm{~K}$, holding time $60 \mathrm{~min}$ ).

reaction temperature of $573 \mathrm{~K}$. Two distinct periods can be iden tified: a "fast heating" period in which the reactor temperature increases from room temperature to $523 \mathrm{~K}$ in about $1015 \mathrm{~min}$, 
followed by a "slow heating" period in which the temperature steadily increases towards the reaction temperature in about $2530 \mathrm{~min}$. Therefore, blackcurrant pomace spends the major part of the heating time at relatively high temperature in subcritical conditions before reaching the reaction temperature, which might explain why the yields seem little affected by the holding time. In addition, the long heating period of the batch reactor might be detrimental to the bio oil yield, as it would allow more secondary polymerisation reactions to occur and produce more char. In batch mode, the char amount is therefore probably higher than what could be obtained using a continuous unit with shorter heating periods. It has been shown before that longer heating times lead to higher char yields [29].

In this set of experiments, the yields seem little affected by the holding time, due to the rapidity of the reactions in the conditions of the study. This directs further studies towards the use of continuous conversion units with shorter heating times and reduced residence times. Achieving high bio oil yields in short residence times is particularly important when considering development of a continuous process, because it would decrease the size of the conversion units and therefore capital costs.

\subsubsection{Effect of biomass concentration}

The solids loading at the inlet of the conversion unit is a crucial process variable for hydrothermal liquefaction, since it directly impacts the energy consumption of the process. To date, mass ra tios between dry biomass and water around 0.15 are achievable for continuous feeding of HTL units [3], although pre treatment methods could increase this ratio to 0.2 [36]. Solid loadings around $1520 \%$ mass fraction are generally needed to ensure the economic benefits of the process, while lower concentrations might reduce its economic advantages because of high capital costs and high energy consumption [2]. The amount of water in the slurry is important as it is as much a reactant (e.g. hydrolysis of bio polymers) as a solvent in HTL. Therefore we decided to evaluate the influence of the biomass loading on HTL of blackcurrant pomace, at a fixed temperature of $573 \mathrm{~K}$ and a fixed holding time of $60 \mathrm{~min}$. Three mass fractions of dry biomass in the reaction slurry were used: $0.05,0.14$ and 0.29 . Fig. 5 shows the results of the experi ments on the products and carbon distribution. Global mass bal ances and carbon balances are relatively good for this set of experiments, as they vary from $91 \%$ to $109 \%$.

Results of the experiments show that the bio oil yield decreases from $29 \%$ to $24 \%$ of the initial dry mass of biomass with increasing biomass loadings from 0.05 to 0.29 , while the char amount in creases from $35 \%$ to $37 \%$ of the initial mass of dry matter. These results are consistent with results from the literature, which generally report a decrease of the bio oil yield with increasing biomass concentrations [37,38]. At high biomass concentrations, reactive intermediates in the aqueous phase and the bio oil are present in higher amounts in the reaction medium. The probability of repolymerisation reactions between reactive fragments leading to char formation might be consequently increased compared to more diluted cases.

Secondly, the availability of liquid water might be playing an important role. In batch mode, the pressure is self generated and can be described as a function of the reaction temperature, the amount of water and of gas produced. The amount of water introduced in the reactor determines whether it is in the liquid state, the gaseous state or at liquid vapour equilibrium when the reaction temperature is reached. Liquid vapour equilibrium calcu lations reported in the supplementary information show that the fraction of evaporated water increases with increasing dry biomass concentration. This means that less water is available in the liquid phase at higher biomass concentrations. At low biomass

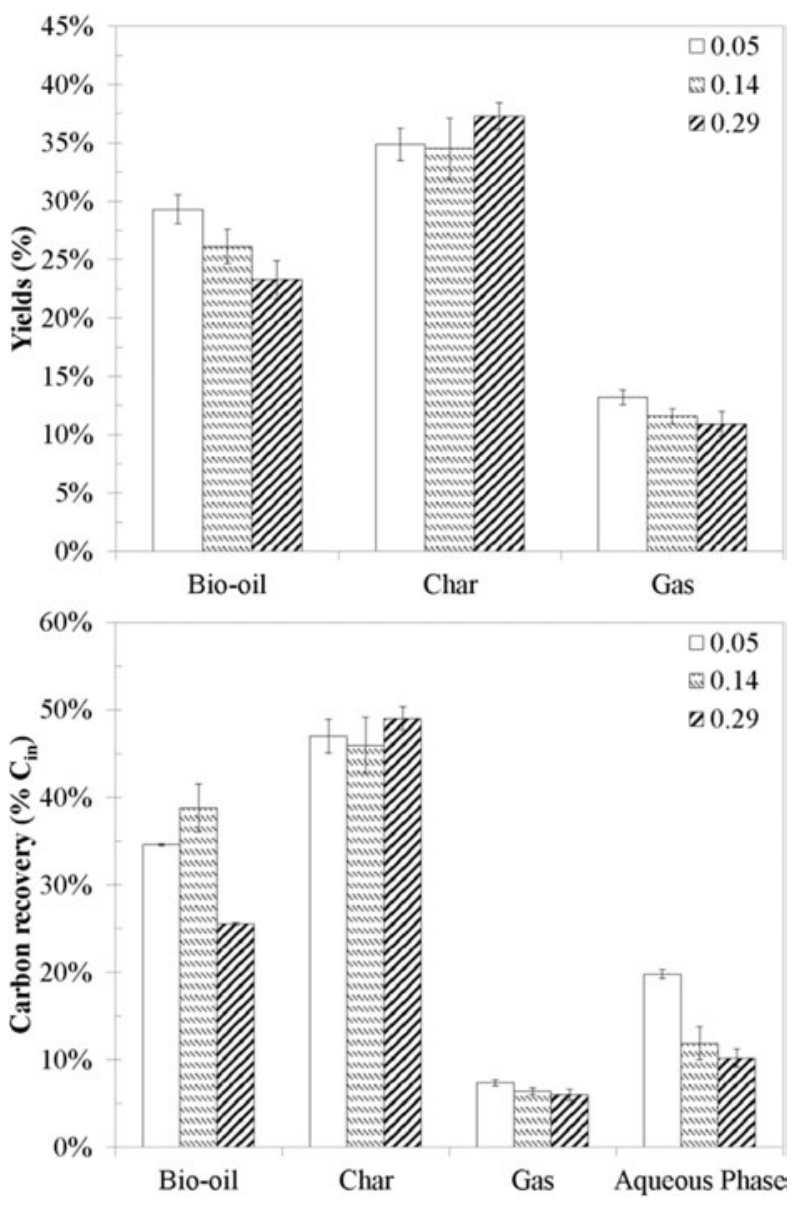

Fig. 5. Effect of the mass fraction of dry biomass in the slurry on products distribution and carbon recovery (reaction temperature $573 \mathrm{~K}$; holding time $60 \mathrm{~min}$ ).

concentrations, more water molecules per unit molecules of biomass are therefore available; increasing both the extraction and solvation powers, as well as it favours degradation of the biomass in liquid phase. This could be one explanation of higher bio oil for mation at low biomass concentrations.

Yet, the majority of water remains in the liquid state in the conditions of the experiments. An additional factor that could explain our experimental results might be the reduced contact between the solid biomass and water at high biomass concentra tions. When the mass fraction of dry biomass in the slurry increases from 0.05 to 0.29 , we estimate that the volume ratio between dry biomass and water increases from 0.1 to 0.4 . It is therefore likely that a certain fraction of the biomass is poorly in contact with liquid water. Thus, at (very) high biomass to water ratios, different reac tion mechanisms might be driven. In these conditions, interactions between biomass and water molecules in liquid phase are less important, and the reactivity between blackcurrant pomace and the vapour phase might be more important. Especially, organic molecules can be formed in the gaseous phase. Even though it is mainly composed by $\mathrm{CO}_{2}$ and low amounts of $\mathrm{CO}, \mathrm{H}_{2}$ and $\mathrm{C}_{1} \mathrm{C}_{3}$ hydrocarbons, Madsen et al. [39] recently reported that organic compounds such as thiols, olefins and aromatic compounds can account for up to $4 \%$ of the volume of the gas phase produced during HTL of dried distillers grains with solubles. In our experi ments, we observed a lower mass balance closure for the experi ments at the highest biomass concentration, which can be partially 
explained by this behaviour. However, we could not analyse all possible organic species in the gaseous phase, due to lack of adapted equipment. Measured species are limited to $\mathrm{N}_{2}, \mathrm{H}_{2}, \mathrm{CO}$, $\mathrm{CO}_{2}$, and $\mathrm{C}_{1} \mathrm{C}_{3}$ hydrocarbons.

Therefore, combined effects might explain the decrease of bio oil yield at high biomass concentrations: increased repolymerisa tion reactions leading to char formation because of higher con centrations of reactive intermediates, lower availability of liquid water in the reactor, and reduced contact between biomass and liquid water in the reactor, driving different reaction mechanisms.

We observed in this section that low biomass concentrations lead to higher oil yields. In addition, from a process development perspective, continuous feeding of the biomass slurry requires sufficient dilution of biomass so that it can be pumped properly into the reactor without causing any plugging issues. Using diluted feed slurries leads however to higher energy consumption: it would cost around $34 \%$ more energy to heat water from $293 \mathrm{~K}$ to $573 \mathrm{~K}$ in the more diluted case considered (0.05), compared to the more concentrated case (0.29). It seems therefore preferable to use biomass loadings as high as possible, to reduce the energy input needed to heat water to the desired reaction temperature. Using concentrated feed slurries would also reduce the overall di mensions of the equipment and the wastewater treatment re quirements, leading to reduction of the capital costs. A compromise has therefore to be found between high bio oil recovery (favoured in diluted conditions) and process development considerations. From our test points, we consider the intermediate concentration (0.14) to be a good compromise between process development considerations and bio oil recovery. In addition, this intermediate concentration is close to what is technologically achievable today [3]. A thorough study of processing costs might however be necessary to identify the optimal concentration from an economic point of view.

\subsection{Effect of addition of sodium hydroxide}

As discussed in the introduction, alkali catalysts are often used in the HTL process. In this section we evaluate the effect of adding sodium hydroxide $(\mathrm{NaOH})$ to the reaction medium. Then, we focus briefly on the sodium distribution between phases.

\subsubsection{Evolution of yields and carbon distributions}

The effect of using $\mathrm{NaOH}$ to vary the initial $\mathrm{pH}$ of the feed was evaluated at a fixed temperature of $573 \mathrm{~K}$ and a fixed holding time of $60 \mathrm{~min}$. Initial pH ranged from 3.1 (natural acidity of the mixture, without $\mathrm{NaOH}$ addition) to 12.8 (corresponding to a $\mathrm{NaOH}$ to dry matter mass ratio of 9\%). Fig. 6 shows the effect of adding sodium hydroxide on the products and carbon distribution. Global mass balances and carbon balance closures vary from $99 \%$ to $111 \%$, which is relatively good considering the experimental error for this set of experiments.

The results show that using $\mathrm{NaOH}$ leads to a reduction of the char yield, corresponding to a higher solubilisation of the organic matter in the aqueous phase. The reduction of the char yield is especially important at higher $\mathrm{NaOH}$ to dry matter ratios (e.g. 9\%). Carbon recovery in the aqueous phase increases from $12 \%$ of the initial mass of carbon at $\mathrm{pH}_{\text {in }}=3.1$ (case without $\mathrm{NaOH}$ ), to $25 \%$ of the initial mass of carbon at $\mathrm{pH}_{\text {in }}=12.8$ (corresponding to a $\mathrm{NaOH}$ to dry matter mass ratio of $9 \%$ ). This observation means that more water soluble molecules are formed when the initial $\mathrm{pH}$ of the feed increases, and is consistent with results reported elsewhere in the literature [40 42]. As well, using $\mathrm{NaOH}$ as additive increases the bio oil yield from $26 \%$ of the initial dry mass of blackcurrant pomace at $\mathrm{pH}_{\text {in }}=3.1$ to $31 \%$ of the initial dry mass of biomass at $\mathrm{pH}_{\mathrm{in}}=12.8$. The relative decrease observed at $\mathrm{NaOH}$ mass loadings

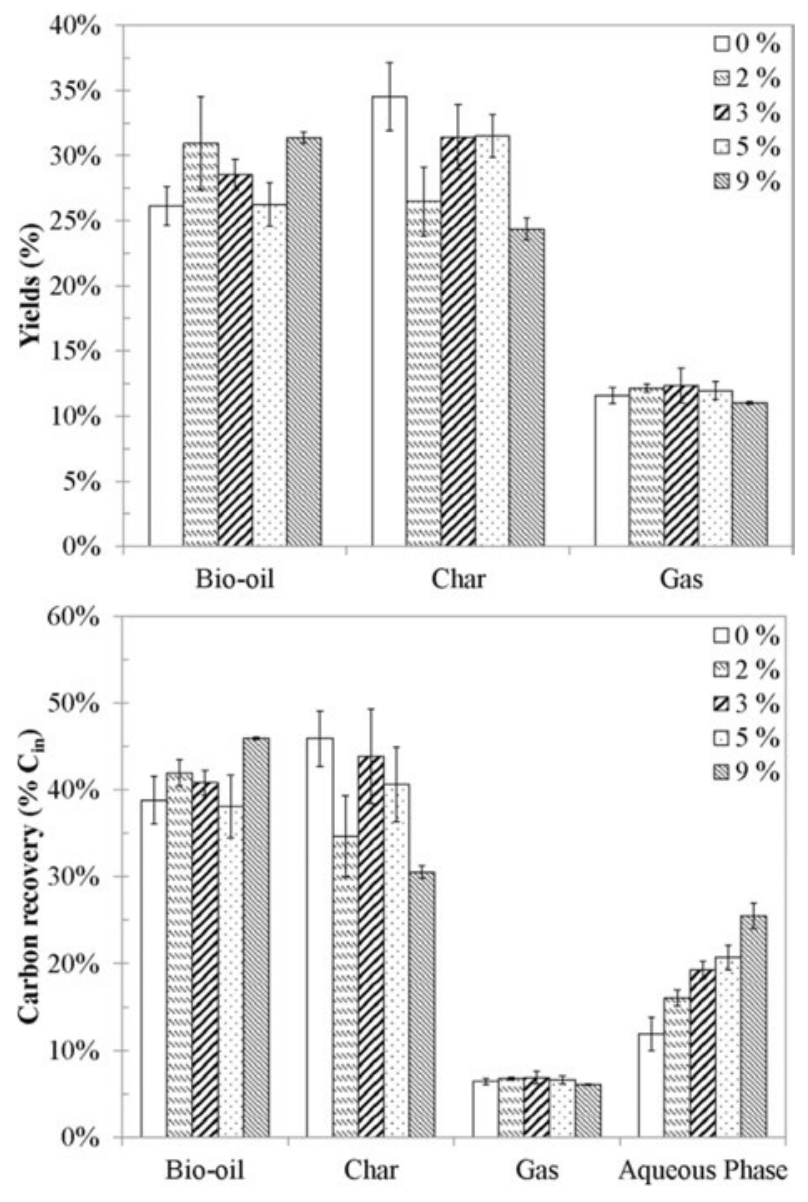

Fig. 6. Effect of $\mathrm{NaOH}$ to dry matter ratio on products distribution and carbon recovery (reaction temperature $573 \mathrm{~K}$, holding time $60 \mathrm{~min}$ ).

of $3 \%$ and $5 \%$ could be partially explained by the aspect of the raw organic residue recovered in these experiments: it was a tarry and extremely sticky material. Solvent extraction was therefore quite hard to perform on this raw organic residue. Globally, using $\mathrm{NaOH}$ impacts the distribution between bio oil and char, and the pro portion of organic molecules in aqueous phase.

The decrease of the amount of char in favour of the organic content of the aqueous phase is mainly due to two beneficial effects of $\mathrm{NaOH}$ for HTL. Firstly, hydroxide ions can neutralise connecting molecules acting as polymerisation intermediates in the formation of char. For instance, hydroxide ions neutralise the carboxylic acids formed during hydrothermal conversion of biomass. It has been observed that polymerisation reactions can occur between car boxylic groups in the aqueous phase and hydroxyl groups at the surface of the residue, forming ester bonds and yielding more char [24]. By reacting with hydroxide ions, carboxylic acids remain in the aqueous phase as carboxylate ions, as shown in Equation (1). This is illustrated by the decrease of the $\mathrm{pH}$ of the aqueous phase after the reaction, which was measured at 5.3 when no $\mathrm{NaOH}$ was added (Fig. 7). Therefore, using $\mathrm{NaOH}$ avoids polymerisation because carboxylic acids are neutralised and cannot participate in conden sation reactions $[24,43]$.

$\mathrm{RCO}_{2} \mathrm{H}+\mathrm{NaOH} \rightarrow \mathrm{RCO}_{2}^{-}+\mathrm{Na}^{+}+\mathrm{H}_{2} \mathrm{O}$

The use of $\mathrm{NaOH}$ influences the reaction pathways occurring in subcritical water, depending on the biomass composition. As 


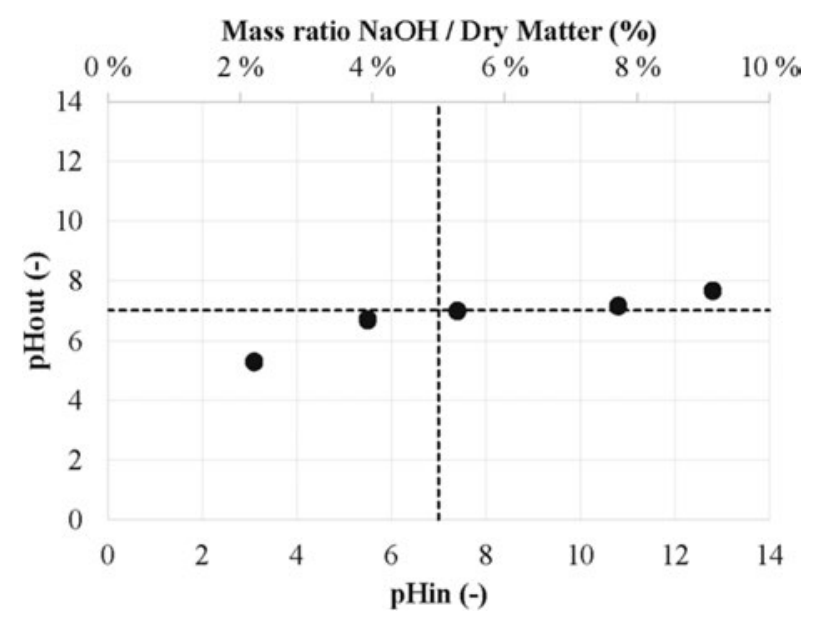

Fig. 7. Comparison of initial $\left(\mathrm{pH}_{\mathrm{in}}\right)$ and final $\left(\mathrm{pH}_{\mathrm{out}}\right) \mathrm{pH}$ of aqueous phases at various $\mathrm{NaOH}$ loadings.

shown in Table 1, blackcurrant pomace is mainly composed of fi bres, with a total fibre (NDF) content representing $61.7 \%$ of the total mass of dry matter. Especially, the $A D F$ and $A D L$ contents are high, meaning that the fibres are both rich in cellulose and lignin. Hy drothermal liquefaction of cellulosic polymers produces sugar degradation products: furans, aldehydes, ketones and carboxylic acids $[44,45]$. Particularly, acidic conditions drive the reaction mechanism towards dehydration of sugars, forming mainly furan derivatives such as 5 (hydroxymethyl) furfural and furfural which can polymerise and increase char formation [40,46]. With increasing $\mathrm{pH}$, reaction mechanisms shift to fragmentations such as retro aldol condensations, leading to the formation of short chain polar compounds, mainly found in the aqueous phase: aldehydes, ketones, and ultimately carboxylic acids [40]. This could partially explain the increased solubilisation of organic matter in the aqueous phase.

While lignin is poorly reactive in acidic conditions, base catalysed hydrolysis with sodium hydroxide is an efficient way to achieve depolymerisation and yield phenol monomers and dimers in the aqueous phase [41]. Base catalysed depolymerisation of the high amount of lignin contained in blackcurrant pomace through hydrolysis could help understanding the better degradability of biomass and the increased solubilisation of organic matter in the aqueous phase. The seeds are lignin rich, and using $\mathrm{NaOH}$ allows good degradation of these particular structures, as shown in Fig. 8. In presence of $\mathrm{NaOH}$, the seeds develop a porous surface: the for mation of pores could enhance the liberation of reserve molecules such as proteins and fatty acids contained in the endosperm of the seed, which are important contributors to the bio oil yield.

Inhibition of char formation can also be explained by the fact that using $\mathrm{NaOH}$ provides a more reductive environment than in acidic conditions. In fact, alkali salts (here $\mathrm{NaOH}$ ) have been iden tified before as promoters of the Water Gas shift reaction [47]. Hydroxide ions $\mathrm{OH}^{-}$react with $\mathrm{CO}_{2}$, which is solubilised in the form of carbonates (Equation (3)). We observed in our experiments an increase of the concentration of inorganic carbon in the aqueous phase, corresponding to higher $\mathrm{CO}_{2}$ solubilisation. The reaction between $\mathrm{CO}_{2}$ and $\mathrm{OH}^{-}$moves forward the equilibrium towards $\mathrm{H}_{2}$ formation (Equations (2) (4)). $\mathrm{H}_{2}$ can act as a reducing agent, limiting condensation reactions between polymerisation in termediates, therefore reducing char formation. We observed in our experiments an increase of the amount of $\mathrm{H}_{2}$ produced in the gas phase, which shows the positive effect of $\mathrm{NaOH}$ on the Water
Gas Shift reaction.

$$
\begin{aligned}
& \mathrm{CO}+\mathrm{H}_{2} \mathrm{O} \rightarrow \mathrm{CO}_{2}+\mathrm{H}_{2} \\
& 2 \mathrm{Na}^{+}+2 \mathrm{OH}^{-}+\mathrm{CO}_{2} \rightarrow 2 \mathrm{Na}^{+}+\mathrm{CO}_{3}^{2-}+\mathrm{H}_{2} \mathrm{O} \\
& \mathrm{CO}+2 \mathrm{Na}^{+}+2 \mathrm{OH}^{-} \rightarrow \mathrm{H}_{2}+2 \mathrm{Na}^{+}+\mathrm{CO}_{3}^{2-}
\end{aligned}
$$

\subsubsection{Sodium recovery after the conversion}

Adding sodium hydroxide to the reaction medium has an important positive effect on the degradability and bio oil produc tion by hydrothermal liquefaction of blackcurrant pomace. As dis cussed in the previous paragraph, hydroxide ions $\mathrm{OH}^{-}$take part in reactions that avoid char formation. According to equations (2) and (4), the majority of sodium ions $\mathrm{Na}^{+}$should remain in the aqueous phase. However, adding sodium hydroxide to the reaction medium could also lead to favouring saponification reactions with fatty acids contained in the biomass and to a decrease of the bio oil quality. We therefore decided to evaluate the sodium distribution after HTL of blackcurrant pomace, to determine whether the bio oil is affected by saponification reactions.

Table 2 shows the sodium recovery in the aqueous phase (determined by ion chromatography), and the ash contents of the bio oil and char samples. Between $58 \%$ at $\mathrm{pH}_{\text {in }}=5.5$ and $72 \%$ at $\mathrm{pH}_{\text {in }}=12.8$ of the initial mass of sodium in the reactor is recovered in the aqueous phase. Ash contents of the bio oil are low, compared to ash contents of the char. This indicates that the remaining frac tion of sodium is mainly distributed in the char. Yet, ash contents of both char and bio oil increase with increasing $\mathrm{NaOH}$ concentra tions, indicating a certain transfer. A small saponification effect is observed in the bio oil fraction when adding $\mathrm{NaOH}$ to the reaction medium. This transfer could be detrimental to the oil quality at higher $\mathrm{NaOH}$ concentrations. Direct combustion of bio oils with non negligible ash contents may lead to problems such as corro sion and deposit in the equipment.

\subsection{Characterisation of the bio oil}

In this section, we focus on characterisation of the bio oil pro duced by HTL of blackcurrant pomace. We first report the results of thermogravimetric analysis (TGA), which was proven before as an effective and useful method to analyse the boiling point distribu tion of bio oils produced by hydrothermal liquefaction [48,49]. TGA can be considered as a small scale distillation that can be used to estimate the boiling fractions of bio oils. Then, we report the results of GC MS analysis of the volatile fraction of the bio oil, as well as some physical and chemical properties. Characterisation of the bio oil gives useful information for further upgrading.

\subsubsection{Thermogravimetric analysis of the bio oil}

Thermogravimetric analysis of the bio oil obtained at $573 \mathrm{~K}$ and 60 min holding time in the absence of $\mathrm{NaOH}$ was performed to evaluate its volatility. We reported in a previous paper that using $\mathrm{NaOH}$ has a limited influence on the volatility of HTL bio oils [31]. The results of the TG analysis are shown in Fig. 9. The boiling point distribution was described according to the terminology and clas sification proposed by Speight for petroleum products [30]. For our samples, the gas fraction (boiling points $<288 \mathrm{~K}$ ) is not applicable.

The evaporation behaviour of the bio oil shows that it is mainly constituted of a medium naphtha fraction, and of high boiling constituents. High boiling point fractions (b.p. > $505 \mathrm{~K}$ ) represent $53 \%$ mass fraction of the total bio oil. On the other hand, the bio oil 


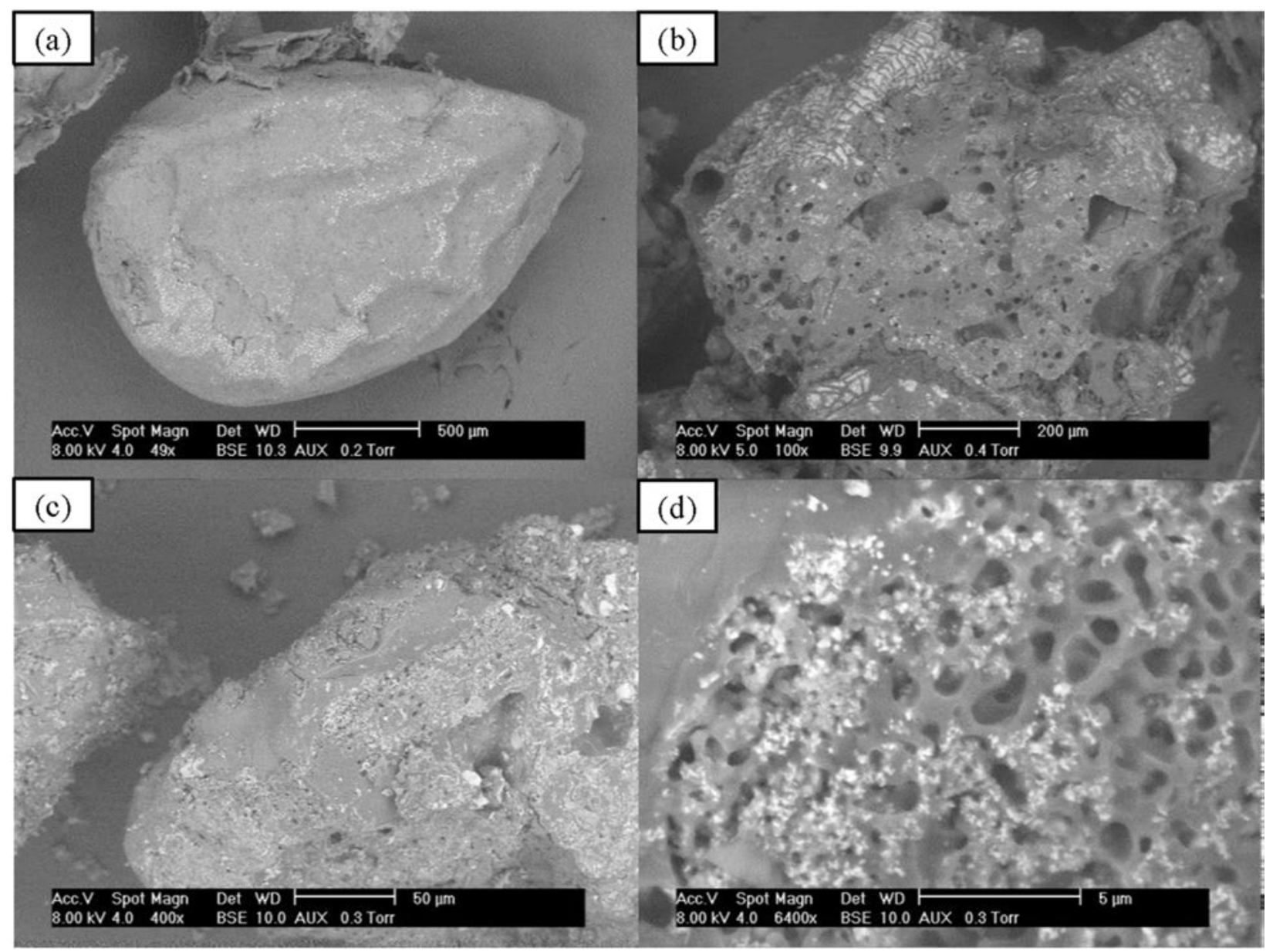

Fig. 8. SEM images of (a) raw blackcurrant seed, (b) char after $\mathrm{HTL}$ at $\mathrm{pH}_{\text {in }} \quad 5.5$ ( $\mathrm{NaOH}$ to dry matter mass ratio $\quad 2 \%$ ), (c,d) char after $\mathrm{HTL}$ at $\mathrm{pH}$ in $\quad 12.8$ ( $\mathrm{NaOH}$ to dry matter mass ratio $9 \%$.

Table 2

Sodium recovery in aqueous phase $\left(\mathrm{NaR}_{\mathrm{A}}\right)$ and ash contents of bio-oil and char samples for HTL of blackcurrant pomace at various initial pH of the feed (reaction temperature $573 \mathrm{~K}$; holding time $60 \mathrm{~min}$ ).

\begin{tabular}{lllll}
\hline $\mathrm{pH}_{\text {in }}(-)$ & $\begin{array}{l}\mathrm{NaOH} \text { to dry matter ratio } \\
(\%)\end{array}$ & $\mathrm{NaR}_{\mathrm{A}}(\%)$ & Ash content in bio-oil (\%) \\
\hline 3.1 & $0 \%$ & $5 \pm 1$ & $<0.1$ & \\
5.5 & $2 \%$ & $58 \pm 12$ & 0.1 & $7.0 \pm 0.3$ \\
7.4 & $3 \%$ & $73 \pm 12$ & 0.2 & $9.3 \pm 0.8$ \\
10.8 & $5 \%$ & $76 \pm 16$ & 1.0 & $9.8 \pm 0.5$ \\
12.8 & $9 \%$ & $72 \pm 1$ & 5.3 & 9.7 \\
\hline
\end{tabular}

has a small fraction of low boiling point constituents. This obser vation might be explained by the bio oil recovery procedure: low boiling point molecules are evaporated along with ethyl acetate, which is observed by GC MS analysis of the bio oil before and after evaporation [31].

While TG analysis is a useful tool to get insights on the distil lation potential of the bio oil, it should be kept in mind that not only the boiling points but also the chemical nature of the mole cules is important for further upgrading steps. In the following section, we present the molecular composition of the bio oil ob tained by GC MS analysis.

\subsubsection{Molecular composition by GC MS analysis}

The molecular composition of the volatile fraction of the bio oil obtained after HTL of blackcurrant pomace was analysed using GC MS. A typical chromatogram of the bio oil (before evaporation of ethyl acetate) is shown in Fig. 10.

As illustrated by the chromatogram, the bio oil is a very complex mixture formed by more than 300 different compounds. The complexity of the mixtures makes the exhaustive identification of the bio oil composition difficult, due to many co eluting peaks and many similar structures leading to similar identifications by the mass spectral database for different retention times. Even though GC MS analysis is limited by the complex composition of the mixture, it is possible to identify the main molecules. We provide in the supplementary information a list of the 50 first compounds in terms of relative peak areas, which can be used as an indication about the chemical composition of the bio oil. These compounds 

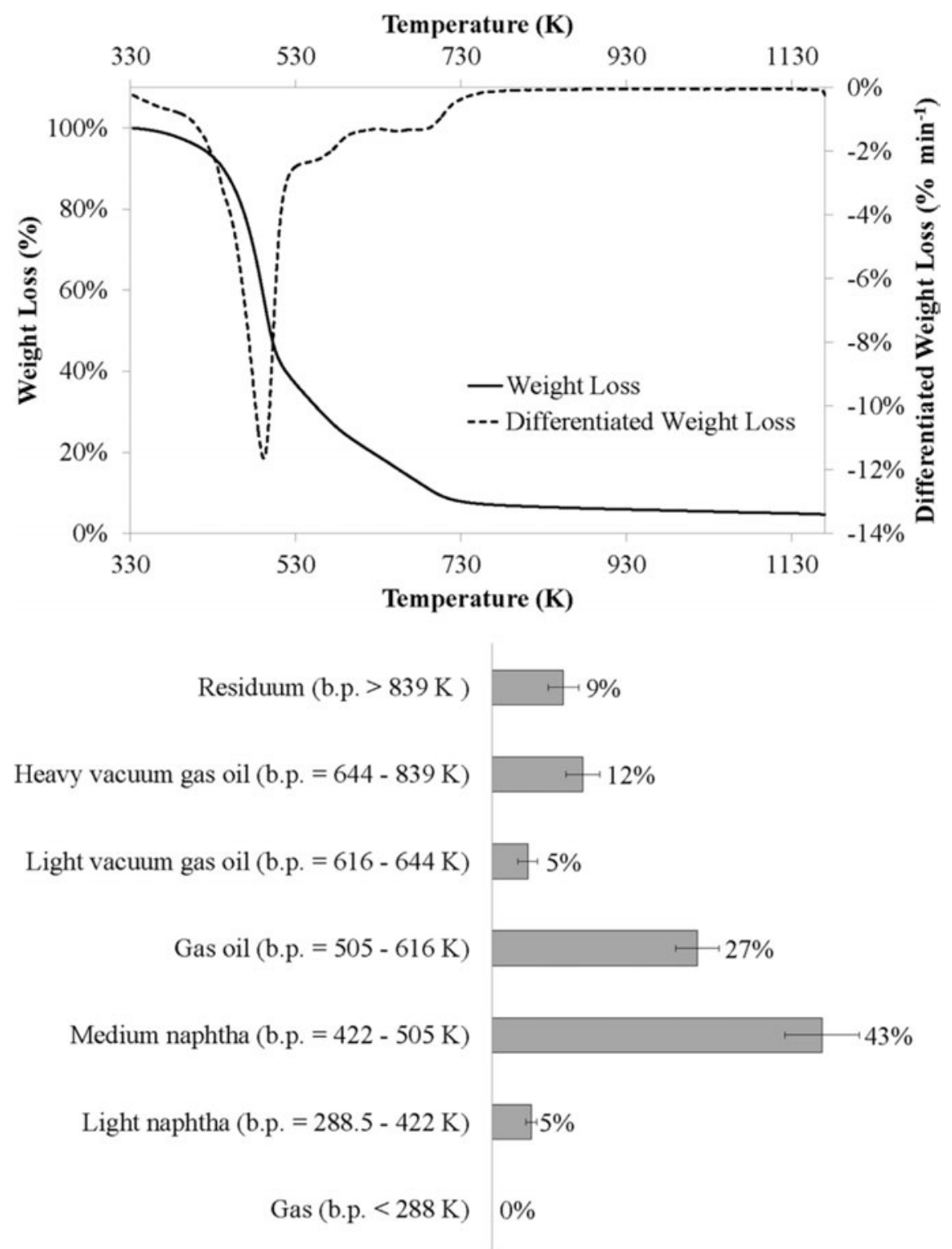

Fig. 9. TG analysis (a) and boiling-point distribution (b) of the bio-oil produced by HTL of blackcurrant pomace (reaction temperature $573 \mathrm{~K}$, holding time 60 min).

are lumped as several chemical families in Fig. 11, and represent $76.2 \%$ of the total area in the chromatogram.

The volatile fraction of the bio oil is mainly formed by heavy compounds such as fatty acids and their derivatives which repre sent more than $30 \%$ of the total peak area, eluting at retention times higher than $45 \mathrm{~min}$. These compounds are fatty acid alkyl esters, long chain amides and fatty acids originating from the lipid content of blackcurrant pomace, mainly found in the seeds. Lipids in the form of triglycerides are hydrolysed in subcritical water and react subsequently with alcohols to form esters and with amino acids originating from the protein content of blackcurrant pomace to form amides.

Other detected molecules are phenol derivatives at retention times between 26 and 35 min: they are mainly produced by hy drolysis of lignin and subsequent degradation of its monomers, and are relatively stable in the conditions of the study. A large number of nitrogenous compounds were also detected at retention times between 30 and $61 \mathrm{~min}$. Structures vary from long chain amides to simple aromatic rings such as pyridine, pyrazine, pyridinol or indole derivatives. These molecules obviously originate from the protein content of blackcurrant pomace: amino acids degrade in subcritical water to form carboxylic acids and amines which can participate to interaction reactions to form bigger nitrogenous structures, for instance via the Maillard reactions with sugars [50,51], or condensation with fatty acids to form amides [52,53]. Finally, a certain number of light structures were also detected at small retention times: they are mainly linear ketones, aldehydes, cyclopentenones, pyridines and pyrazines. Such molecules mainly derive from hydrothermal degradation of cellulosic polymers, and to a certain extent from hydrothermal conversion of proteins. In subcritical water, cellulose and hemicelluloses release mono saccharides by hydrolysis, which then degrade to give mainly light polar molecules, as well as polymeric char [54].

It is important to notice that GC MS analysis of the bio oil only 


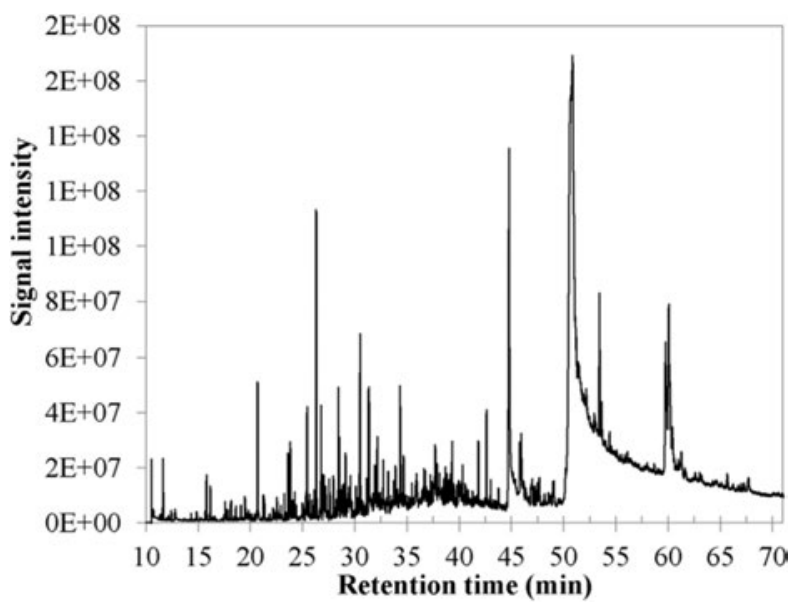

Fig. 10. Chromatogram of the bio-oil produced by HTL of blackcurrant pomace (reaction temperature $573 \mathrm{~K}$, holding time $60 \mathrm{~min}$ ).

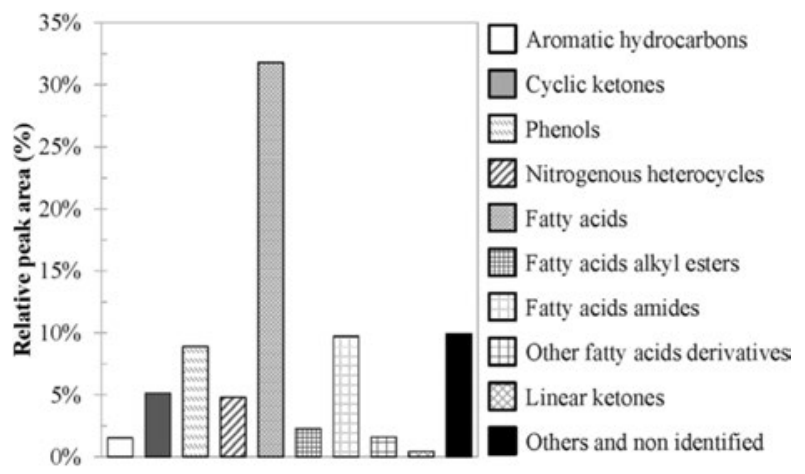

Fig. 11. Main chemical families found by GC-MS analysis of the bio-oil.

provides partial information, because it often cannot identify molecules with high boiling points. The TG analysis of the bio oil showed that it contains many high boiling point molecules. From the TG analysis, it is evaluated that only $57 \%$ mass fraction of the total bio oil is analysed by GC MS (boiling points $<523 \mathrm{~K}$ ). The remaining fraction corresponds to high boiling point molecules, and should be analysed by other techniques adapted to non volatile compounds.

\subsubsection{Physico chemical properties of the bio oil}

Table 3 shows the physico chemical properties of the bio oil produced at $573 \mathrm{~K}, 60$ min holding time in the absence of $\mathrm{NaOH}$.

From the results, it can be concluded that the produced bio oil is interesting for energy applications. It has low moisture content along with a higher heating value of $35.9 \mathrm{MJ} \mathrm{kg}^{-1}$. From the cor responding mass yield, the energy recovery in the bio oil is esti mated at $49 \%$ of the initial energy contained in the feedstock. Elemental analysis of the bio oil shows that it contains certain amounts of nitrogen and oxygen, which would direct the upgrading process towards hydrodeoxygenation and hydrodenitrogenation steps. The high Total Acid Number (TAN) can be linked to the large proportion of fatty acids detected in the GC MS analysis, and to the presence of a non negligible amount of acidic groups such as hy droxyl groups in phenols. The relatively high iodine value measured in the bio oil shows that it contains insaturations that could be detrimental to the stability and storage potential of the bio oil. The
Table 3

Properties of the bio-oil obtained by HTL of blackcurrant pomace (reaction temperature $573 \mathrm{~K}$, holding time $60 \mathrm{~min}$ ).

\begin{tabular}{|c|c|}
\hline & Bio-oil \\
\hline Moisture content (\%) & $<5$ \\
\hline \multicolumn{2}{|l|}{ Elemental composition (\% of dry matter) } \\
\hline $\mathrm{C}$ & 73.3 \\
\hline $\mathrm{H}$ & 9.6 \\
\hline $\mathrm{N}$ & 3.4 \\
\hline $\mathrm{S}$ & 0.1 \\
\hline O (by difference) & 13.6 \\
\hline $\operatorname{HHV}\left(\mathrm{MJ} \mathrm{kg}{ }^{1}\right)$ & 35.9 \\
\hline Ash content at $823 \mathrm{~K}$ (\% of dry matter) & $<0.1$ \\
\hline Total Acid Number (mg of $\mathrm{KOH}$ per gram of bio-oil) & 134 \\
\hline Iodine value ( $\mathrm{g}$ of $\mathrm{I}_{2}$ per $100 \mathrm{~g}$ of bio-oil) & 150 \\
\hline Dynamic viscosity at $298 \mathrm{~K}$ (Pa s) & 1.7 \\
\hline Density at $288 \mathrm{~K}\left(\mathrm{~kg} \mathrm{~m}^{3}\right)$ & 960990 \\
\hline
\end{tabular}

high viscosity can be linked with the results of TG analysis, which showed that the bio oil contained a majority of high boiling point constituents, therefore high molecular weight structures. The high acidity and viscosity values underline the need for upgrading before any use as fuel in a boiler or an engine. Comparison with standard commercial fuels is an interesting way to evaluate the need for upgrading, as we recently reported [31].

\section{Conclusion}

This study demonstrates the feasibility of applying hydrother mal liquefaction (HTL) to process wet lignocellulosic residues generated by the agricultural and food processing industries, through the example of blackcurrant pressing residues. Bio oils mass yields of $2431 \%$ were obtained, higher than the initial lipid content of the biomass. This means that HTL is an efficient process to produce oils in high yields from wet blackcurrant pomace.

The relatively high amount of char and the low influence of holding times on the results suggests that a reactor with shorter heating and reaction times might be adapted, i.e. with continuous operation. It would both reduce the volume of installations and char formation, in favour of better bio oil yields by avoiding repo lymerisation. Low biomass concentrations enhance bio oil pro duction, which underlines the need for a compromise between bio oil recovery and process development considerations.

Distribution of the products is significantly affected by the use of sodium hydroxide as additive. The bio oil yield is enhanced and the char amount is reduced, both due to a better degradability of blackcurrant pomace in alkaline conditions through hydrolysis of fibres, and to the inhibition of char formation by stabilisation of reactive intermediates.

The analysis of the bio oil by several complementary techniques gives a detailed knowledge of this product. HTL of blackcurrant pomace produces heavy oils with interesting properties for fuel applications. The bio oil has simultaneously high energy content $\left(\mathrm{HHV}=35.9 \mathrm{MJ} \mathrm{kg}^{-1}\right)$, low ash content, and falls in the right boiling point range for upgrading to fungible fuels. Yet, some of its prop erties (e.g. acidity, viscosity) indicates that the bio oil must be upgraded before any use for fuel applications.

\section{Acknowledgements}

The authors would like to acknowledge financial support from the French Research National Agency ANR (LIQHYD project, Grant ANR 12 BIME 0003). The authors are also grateful to Marine Blanchin, Hélène Miller, Sébastien Thiery, Suzanne Anouti and Julien Roussely for technical support and help on analysis of the 
products.

\section{Nomenclature}

\begin{tabular}{|c|c|}
\hline ADF & Acid Detergent Fibres \\
\hline ADL & Acid Detergent Lignin \\
\hline $\mathrm{CT}_{\mathrm{A}}$ & Concentration of total carbon in aqueous phase $\left(\mathrm{g} \mathrm{L}^{-1}\right)$ \\
\hline GC MS & Gas Chromatography Mass Spectrometry \\
\hline HHV & Higher Heating Value $\left(\mathrm{MJ} \mathrm{kg}^{-1}\right)$ \\
\hline HTL & Hydrothermal Liquefaction \\
\hline $\mathrm{m}_{\mathrm{BC}}$ & Mass of dry blackcurrant pomace (g) \\
\hline $\mathrm{m}_{\mathrm{BO}}$ & Mass of bio oil $(\mathrm{g})$ \\
\hline $\mathrm{m}_{\mathrm{C}}$ & Mass of char $(\mathrm{g})$ \\
\hline $\mathrm{m}_{\mathrm{G}}$ & Mass of gas (g) \\
\hline $\mathrm{m}_{\mathrm{NaOH}}$ & Mass of sodium hydroxide (g) \\
\hline $\mathrm{m}_{\mathrm{R}}$ & Mass of raw organic residue $(\mathrm{g})$ \\
\hline $\mathrm{NaR}_{\mathrm{A}}$ & $\begin{array}{l}\text { Sodium recovery in the aqueous phase (\% of initial mass of } \\
\text { sodium in the reactor) }\end{array}$ \\
\hline NDF & Neutral Detergent Fibres \\
\hline SEM & Scanning Electron Microscope \\
\hline SSO & $\begin{array}{l}\text { Proportion of solvent soluble organics in the raw organic } \\
\text { residue (\% mass) }\end{array}$ \\
\hline TAN & Total Acid Number (mg of $\mathrm{KOH}$ per gram of bio oil) \\
\hline TGA & Thermogravimetric Analysis \\
\hline $\mathrm{V}_{\mathrm{A}}$ & Volume of aqueous phase (L) \\
\hline $\mathrm{W}_{\mathrm{R}}$ & Water content of raw organic residue (\% mass) \\
\hline $\mathrm{Y}_{\mathrm{BO}}$ & Bio oil yield (\% of dry mass of blackcurrant pomace) \\
\hline $\mathrm{Y}_{\mathrm{C}}$ & Char yield (\% of dry mass of blackcurrant pomace) \\
\hline $\mathrm{Y}_{\mathrm{G}}$ & Gas yield (\% of dry mass of blackcurrant pomace) \\
\hline
\end{tabular}

\section{Appendix A. Supplementary data}

Supplementary data related to this article can be found at http:// dx.doi.org/10.1016/j.biombioe.2016.10.012.

\section{References}

[1] S.S. Toor, L. Rosendahl, A. Rudolf, Hydrothermal liquefaction of biomass: review of subcritical water technologies, Energy 36 (5) (2011) 23282342.

[2] A.A. Peterson, F. Vogel, R.P. Lachance, M. Froling, M.J. Antal Jr., J.W. Tester, Thermochemical biofuel production in hydrothermal media: a review of suband supercritical water technologies, Energy Environ. Sci. 1 (1) (2008) 3265.

[3] D.C. Elliott, P. Biller, A.B. Ross, A.J. Schmidt, S.B. Jones, Hydrothermal liquefaction of biomass: developments from batch to continuous process, Bioresour. Technol. 178 (2015) 147156.

[4] H. Weingärtner, E.U.F. Franck, Supercritical water as a solvent, Angew. Chem Int. Ed. 44 (18) (2005) 26722692.

[5] T.H. Pedersen, I.F. Grigoras, J. Hoffmann, S.S. Toor, I.M. Daraban, C.U. Jensen, et al., Continuous hydrothermal co-liquefaction of aspen wood and glycerol with water phase recirculation, Appl. Energy 162 (2016) 10341041.

[6] D. Lopez Barreiro, W. Prins, F. Ronsse, W. Brilman, Hydrothermal liquefaction (HTL) of microalgae for biofuel production: state of the art review and future prospects, Biomass Bioenergy 53 (2013) 113127.

[7] M. Deniel, G. Haarlemmer, A. Roubaud, E. Weiss-Hortala, J. Fages, Energy valorisation of food processing residues and model compounds by hydrothermal liquefaction, Renew. Sustain. Energy Rev. 54 (2016) 16321652.

[8] F. Girotto, L. Alibardi, R. Cossu, Food waste generation and industrial uses: a review, Waste Manage 45 (2015) 3241.

[9] Food Wastage Footprint: Impacts on Natural Resources, Food and Agriculture Organization of the United Nations, 2013, ISBN 978-92-5-107752-8.

[10] Final Report - Preparatory Study on Food Waste across EU27, European Comission, 2010, ISBN 978-92-79-22138-5.

[11] R. Vardanega, J.M. Prado, M.A.A. Meireles, Adding value to agri-food residues by means of supercritical technology, J. Supercrit. Fluids 96 (2014) 217227.

[12] J. Vigano, A.P. Da Fonseca Machado, J. Martínez, Sub- and supercritical technology applied to food waste processing, J. Supercrit. Fluids 96 (2014) 272286.

[13] Global Initiative on Food Loss and Waste Reduction, Food and Agriculture Organization of the United Nations, 2014.

[14] A. Liu, Y. Park, Z. Huang, B. Wang, R.O. Ankumah, P.K. Biswas, Product identification and distribution from hydrothermal conversion of walnut shells, Energy fuels. 20 (2) (2006) 446454.

[15] H. Mazaheri, K.T. Lee, S. Bhatia, A.R. Mohamed, Sub/supercritical liquefaction of oil palm fruit press fiber for the production of bio-oil: effect of solvents, Bioresour. Technol. 101 (19) (2010) 76417647.

[16] M.K. Akalın, K. Tekin, S. Karagöz, Hydrothermal liquefaction of cornelian cherry stones for bio-oil production, Bioresour. Technol. 110 (2012) 682687.

[17] F. Salak, S. Daneshvar, J. Abedi, K. Furukawa, Adding value to onion (Allium cepa L.) waste by subcritical water treatment, Fuel Process. Technol. 112 (2013) 8692.

[18] F. Wang, Z. Chang, P. Duan, W. Yan, Y. Xu, L. Zhang, et al., Hydrothermal liquefaction of Litsea cubeba seed to produce bio-oils, Bioresour. Technol. 149 (2013) 509515

[19] F.M. Yedro, J. Garcia-Serna, D.A. Cantero, F. Sobron, M.J. Cocero, Hydrothermal hydrolysis of grape seeds to produce bio-oil, RSC Adv. 4 (57) (2014) 3033230339.

[20] Y.H. Chan, S. Yusup, A.T. Quitain, Y. Uemura, M. Sasaki, Bio-oil production from oil palm biomass via subcritical and supercritical hydrothermal liquefaction, J. Supercrit. Fluids 95 (2014) 407412.

[21] K. Tekin, Hydrothermal conversion of russian olive seeds into crude bio-oil using a CaO catalyst derived from waste mussel shells, Energy fuels. 29 (7) (2015) 43824392.

[22] D.J.N. Subagyono, M. Marshall, W.R. Jackson, A.L. Chaffee, Pressurized thermal and hydrothermal decomposition of algae, wood chip residue, and grape marc: a comparative study, Biomass Bioenergy 76 (2015) 141157.

[23] S. Karagöz, T. Bhaskar, A. Muto, Y. Sakata, Hydrothermal upgrading of biomass: effect of $\mathrm{K} 2 \mathrm{CO} 3$ concentration and biomass/water ratio on products distribution, Bioresour. Technol. 97 (1) (2006) 9098.

[24] M. Sugano, H. Takagi, K. Hirano, K. Mashimo, Hydrothermal liquefaction of plantation biomass with two kinds of wastewater from paper industry, J. Mat. Sci. 43 (7) (2008) 24762486.

[25] S. Yin, R. Dolan, M. Harris, Z. Tan, Subcritical hydrothermal liquefaction of cattle manure to bio-oil: effects of conversion parameters on bio-oil yield and characterization of bio-oil, Bioresour. Technol. 101 (10) (2010) 36573664.

[26] G. Haarlemmer, C. Guizani, S. Anouti, M. Deniel, A. Roubaud, S. Valin, Analysis and comparison of bio-oils obtained by hydrothermal liquefaction and fast pyrolysis of beech wood, Fuel 174 (2016) 180188

[27] M. Huet, A. Roubaud, D. Lachenal, Conversion of sulfur-free black liquor into fuel gas by supercritical water gasification, Holzforsch 69 (6) (2015) 751760.

[28] D. Zhou, L. Zhang, S. Zhang, H. Fu, J. Chen, Hydrothermal liquefaction of macroalgae enteromorpha prolifera to bio-oil, Energy fuels. 24 (7) (2010) 40544061.

[29] B. Zhang, M. Von Keitz, K. Valentas, Thermochemical liquefaction of highdiversity grassland perennials, J. Anal. Appl. Pyrolysis 84 (1) (2009) 1824.

[30] J.G. Speight, Distillation, in: Wiley Interscience (Ed.), Handbook of Petroleum Product Analysis, 2001.

[31] S. Anouti, G. Haarlemmer, M. Déniel, A. Roubaud, Analysis of physico-chemical properties of bio-oil from hydrothermal liquefaction of blackcurrant pomace, Energy fuels. 30 (1) (2015) 398406.

[32] J. Akhtar N.AS. Amin, A review on process conditions for optimum bio-oil yield in hydrothermal liquefaction of biomass, Renew. Sustain, Energy Rev. 15 (3) (2011) 16151624

[33] S. Karagöz, T. Bhaskar, A. Muto, Y. Sakata, Comparative studies of oil compositions produced from sawdust, rice husk, lignin and cellulose by hydrothermal treatment, Fuel 84 (7 8) (2005) 875884.

[34] Y. Matsumura, T. Minowa, B. Potic, S.R.A. Kersten, W. Prins, W.P.M. Van Swaaij, et al., Biomass gasification in near- and super-critical water: status and prospects, Biomass Bioenergy 29 (4) (2005) 269292.

[35] T. Rogalinski, K. Liu, T. Albrecht, G. Brunner, Hydrolysis kinetics of biopolymers in subcritical water, J. Supercrit. Fluids 46 (3) (2008) 335341.

[36] I.M. Daraban, L.A. Rosendahl, T.H. Pedersen, S.B. Iversen, Pretreatment methods to obtain pumpable high solid loading wood water slurries for continuous hydrothermal liquefaction systems, Biomass Bioenergy 81 (2015) 437443.

[37] Y. Qu, X. Wei, C. Zhong, Experimental study on the direct liquefaction of Cunninghamia lanceolata in water, Energy 28 (7) (2003) 597606.

[38] K. Anastasakis, A.B. Ross, Hydrothermal liquefaction of the brown macro-alga Laminaria Saccharina: effect of reaction conditions on product distribution and composition, Bioresour. Technol. 102 (7) (2011) 48764883.

[39] R.B. Madsen, P.S. Christensen, K. Houlberg, El Lappa, A.J. Mørup, M. Klemmer, et al., Analysis of organic gas phase compounds formed by hydrothermal liquefaction of Dried Distillers Grains with Solubles, Bioresour. Technol. 192 (2015) 826830.

[40] S. Yin, Z. Tan, Hydrothermal liquefaction of cellulose to bio-oil under acidic, neutral and alkaline conditions, Appl. Energy 92 (2012) 234239.

[41] A. Toledano, L. Serrano, J. Labidi, Improving base catalyzed lignin depolymerization by avoiding lignin repolymerization, Fuel 116 (2014) 617624.

[42] R.W. Thring, Alkaline degradation of ALCELL ${ }^{\circledR}$ lignin, Biomass Bioenergy 7 (1 6) (1994) 125130 .

[43] J.E. Miller, L.R. Evans, J.E. Mudd, K.A. Brown, Batch Microreactor Studies of Lignin Depolymerization by Bases. 2. Aqueous Solvents 2002 May, Sandia National Laboratories, USA, 2002. SAND2002 1318.

[44] T.M. Aida, K. Tajima, M. Watanabe, Y. Saito, K. Kuroda, T. Nonaka, et al., Reactions of d-fructose in water at temperatures up to $400^{\circ} \mathrm{C}$ and pressures up to 100MPa, J. Supercrit. Fluids 42 (1) (2007) 110119.

[45] T.M. Aida, N. Shiraishi, M. Kubo, M. Watanabe, R.L. Smith Jr., Reaction kinetics of d-xylose in sub- and supercritical water, J. Supercrit. Fluids 55 (1) (2010) 208216. 
[46] F. Salak Asghari, H. Yoshida, Acid-Catalyzed production of 5-Hydroxymethyl furfural from d-fructose in subcritical water, Ind. Eng. Chem. Res. 45 (7) (2006) 21632173.

[47] G. Akgül, A. Kruse, Influence of salts on the subcritical water-gas shift reaction, J. Supercrit. Fluids 66 (2012) 207214.

[48] A.B. Ross, P. Biller, M.L. Kubacki, H. Li, A. Lea-Langton, J.M. Jones, Hydrothermal processing of microalgae using alkali and organic acids, Fuel 89 (9) (2010) 22342243.

[49] W.T. Chen, Y. Zhang, J. Zhang, G. Yu, L.C. Schideman, P. Zhang, et al., Hydrothermal liquefaction of mixed-culture algal biomass from wastewater treatment system into bio-crude oil, Bioresour. Technol. 152 (2014) 130139.

[50] A.A. Peterson, R.P. Lachance, J.W. Tester, Kinetic evidence of the maillard reaction in hydrothermal biomass processing: glucose-Glycine interactions in high-temperature, high-pressure water, Ind. Eng. Chem. Res. 49 (5) (2010)
21072117

[51] A. Kruse, P. Maniam, F. Spieler, Influence of proteins on the hydrothermal gasification and liquefaction of biomass. 2. Model compounds, Ind. Eng. Chem. Res. 46 (1) (2007) 8796

[52] S. Chiaberge, I. Leonardis, T. Fiorani, G. Bianchi, P. Cesti, A. Bosetti, et al., Amides in bio-oil by hydrothermal liquefaction of organic wastes: a mass spectrometric study of the thermochemical reaction products of binary mixtures of amino acids and fatty acids, Energy fuels. 27 (9) (2013) 52875297.

[53] S. Changi, M. Zhu, P.E. Savage, Hydrothermal reaction kinetics and pathways of phenylalanine alone and in binary mixtures, ChemSusChem 5 (9) (2012) 17431757.

[54] M. Möller, F. Harnisch, U. Schroder, Hydrothermal liquefaction of cellulose in subcritical water-the role of crystallinity on the cellulose reactivity, RSC Adv. 3 (27) (2013) 1103511044. 